\title{
Influence of environmental temperature on risk of gestational diabetes
}

\author{
Gillian L. Booth MD MSc, Jin Luo MSc, Alison L. Park MSc, Denice S. Feig MD MSc, Rahim Moineddin PhD, \\ Joel G. Ray MD MSc
}

Cite as: CMAJ 2017 May 15;189:E682-9. doi: 10.1503/cmaj.160839

Visual abstract available at www.cmaj.ca/lookup/suppl/doi:10.1503/cmaj.160839/-/DC2

\begin{abstract}
BACKGROUND: Cold-induced thermogenesis is known to improve insulin sensitivity, which may become increasingly relevant in the face of global warming. The aim of this study was to examine the relation between outdoor air temperature and the risk of gestational diabetes mellitus.
\end{abstract}

METHODS: We identified all births in the Greater Toronto Area from 2002 to 2014 using administrative health databases. Generalized estimating equations were used to examine the relation between the mean 30-day outdoor air temperature before the time of gestational diabetes mellitus screening and the likelihood of diagnosis of gestational diabetes mellitus based on a validated algorithm using hospital records and physician service claims.

RESULTS: Over the 12-year period, there were 555911 births among 396828 women. Prevalence of gestational diabetes mellitus was $4.6 \%$ among women exposed to extremely cold mean outdoor air temperatures $\left(\leq-10^{\circ} \mathrm{C}\right)$ in the 30-day period before screening and increased to $7.7 \%$ among those exposed to hot mean 30-day temperatures $\left(\geq 24^{\circ} \mathrm{C}\right)$. Each $10^{\circ} \mathrm{C}$ increase in mean 30-day temperature was associated with a $1.06(95 \%$ confidence interval [Cl] 1.04-1.07) times higher odds of gestational diabetes mellitus, after adjusting for maternal age, parity, neighbourhood income quintile, world region and year. A similar effect was seen for each $10^{\circ} \mathrm{C}$ rise in outdoor air temperature difference between 2 consecutive pregnancies for the same woman (adjusted odds ratio $1.06,95 \% \mathrm{Cl} 1.03-1.08)$.

INTERPRETATION: In our setting, there was a direct relation between outdoor air temperature and the likelihood of gestational diabetes mellitus. Future climate patterns may substantially affect global variations in the prevalence of diabetes, which also has important implications for the prevention and treatment of gestational diabetes mellitus.
$\mathrm{T}$ he impact of climate variability on health has become increasingly relevant given the global rise in air temperatures over the past century. ${ }^{1,2}$ Extreme weather patterns can adversely influence health - directly, as in the case of hyperor hypothermia - and indirectly, by triggering respiratory exacerbations, infectious outbreaks, water-borne diseases and injuries. ${ }^{3}$ However, there is also growing evidence supporting a link between air temperature, metabolic function and energy expenditure. Brown adipose tissue aids with acclimatization to cold through its unique ability to generate heat by uncoupling cellular respiration from mitochondrial adenosine triphosphate (ATP) synthesis. ${ }^{4-6}$ Based on findings from studies involving animals and humans, the effects of brown adipose tissue activation extend beyond thermogenesis, by influencing whole-body metabolism and possibly overall body weight. ${ }^{7-18}$ Small intervention trials involving humans have suggested that even mild exposure to ambient cold - such as lowering a thermostat from $24^{\circ} \mathrm{C}$ to $19^{\circ} \mathrm{C}$ - can increase activity of brown adipose tissue by $30 \%-40 \%$, resulting in substantial improvements in insulin sensitivity. ${ }^{15-18}$ In theory, greater insulin sensitivity should improve glucose handling, but whole-population studies evaluating the potential for cold exposure to reduce glucose mishandling are lacking.

We examined the impact of variation in outdoor air temperature on the risk of gestational diabetes mellitus, a transient form of diabetes arising by midpregnancy. Placental hormones lead to a temporary state of insulin resistance, starting in the second trimester of pregnancy and continuing until delivery..$^{19}$ Gestational diabetes mellitus arises when the compensatory increase in insulin production fails to maintain normal blood glucose levels. This condition affects more than 15 million pregnancies worldwide each year ${ }^{20}$ and can have serious consequences for mother, baby and the delivery process. ${ }^{21-23}$ Hence, gestational diabetes mellitus offers an opportunity to study the short-term effect of ambient outdoor temperature on human metabolism. 


\section{Methods}

\section{Setting}

We used administrative health databases to identify all births to women living in the Greater Toronto Area (including urban and suburban areas of Burlington, Oakville, Mississauga, Brampton, Richmond Hill, Vaughan, Markham, Pickering, Ajax, Whitby and Oshawa, Ontario)..$^{24}$ This region - one of the largest metropolitan areas in North America (about 6 million people) - has a humid continental climate with cold winters and hot summers. All permanent residents of Ontario receive health care under a single government-funded provincial health plan (Ontario Health Insurance Plan [OHIP]). Therefore, anonymized health records - including hospital, physician and laboratory services - are available for more than $99 \%$ of the population.

\section{Study population and data sources}

We used existing linked databases for the province of Ontario, all housed at the Institute for Clinical Evaluative Sciences (ICES, www.ices.on.ca). Individual obstetric deliveries were identified in the Discharge Abstract Database (DAD) of the Canadian Institute for Health Information (CIHI) using previously validated codes from the International Statistical Classification of Diseases and Related Health Problems, 10th revision, Canadian version (ICD10-CA), and patient service and case-mix groups. ${ }^{25,26}$ The MOMBABY Database at ICES includes all inpatient admission records from the Discharge Abstract Database for mothers and their newborns delivered from Apr. 1, 2002 onward (capturing 99\% of all births in Ontario), and deterministically links a mother and newborn. ${ }^{27}$ Each record in the MOMBABY Database contains the gestational age at birth, maternal parity and up to 25 diagnoses.

This study included all women living in the Greater Toronto Area who gave birth between Apr. 1, 2002, and Mar. 31, 2014. Women with an extreme preterm ( $<28$ wk gestation) or postterm ( $>42$ wk gestation) birth were excluded, as were those with pre-gestational diabetes (type 1 or type 2).The latter was ascertained using records from the Ontario Diabetes Database, which has a high sensitivity (86\%) and specificity (97\%) for identifying individuals with nongestational diabetes. ${ }^{28}$ Women who entered the Ontario Diabetes Database more than 120 days before the index birth were considered to have pregestational diabetes and were excluded from the study. We also excluded women who moved to Ontario after their 20th week of gestation to ensure those with pregestational diabetes were not included.

Laboratory claims data were used to identify a date for gestational diabetes mellitus screening, based on the presence of a fee code for a 50-g glucose challenge test (codes L103 or L111). Among a subsample of women who underwent screening for gestational diabetes mellitus at Mount Sinai Hospital, Toronto, we also had results for blood glucose challenge tests.

Records for each woman were linked anonymously across multiple databases using a unique identifier created from encrypted versions of their health card number.

\section{Study exposure}

Our main exposure was mean outdoor air temperature during the 30-day period before a woman's 27th week of pregnancy, the usual time of screening for gestational diabetes mellitus. Historical weather data from Environment Canada was used to derive a 30-day average of each daily high and low air temperature, in degrees celsius, captured at a single weather station at Toronto Pearson International Airport.

\section{Study outcomes}

We followed the participants from the time of their 30-day exposure to outdoor air temperature to the date of obstetrical birth, and assessed for a diagnosis of gestational diabetes mellitus based on a validated algorithm using administrative claims data. We based a diagnosis of gestational diabetes mellitus on the presence of one or more diagnostic codes for diabetes from hospital discharge abstract records (ICD-10-CA codes E10, E11, E13, E14 or O24), or 2 or more physician fee-for-service billing claims bearing a diagnosis of diabetes in the last 120 days of pregnancy (i.e., from 23 wk gestation onward). This algorithm was found to have a sensitivity of $94 \%$ and specificity of $98 \%$ for identifying confirmed cases of gestational diabetes mellitus based on laboratory glucose measurements in response to an oral glucose load. The latter included women who had positive results for 50 -g glucose challenge screening tests ( $\geq 7.8 \mathrm{mmol} / \mathrm{L}$ ) followed by 2 or more abnormalities on an oral glucose tolerance test, or a glucose concentration of $10.3 \mathrm{mmol} / \mathrm{L}$ or more for the 50-g glucose challenge test alone, in accordance with Canadian guidelines for diagnosing gestational diabetes mellitus. $^{29,30}$ These performance characteristics are similar to other published algorithms using administrative claims. ${ }^{31}$

\section{Baseline covariates}

Maternal age, parity and postal code of residence were derived from hospital discharge abstracts for the index pregnancy. Neighbourhood income level was derived from the Canadian Census and assigned to each woman using her postal code of residence at the time of delivery. The Immigration, Refugees and Citizenship Canada database was used to derive the country of birth for women born outside of Canada who were granted permanent residency in Canada as of January 1985..$^{32,33}$ Information on prepregnancy body mass index (BMI) was available for a subset of 36935 births between 2006 and 2011, linked to the Better Outcomes Registry and Network (BORN) data set at ICES.

\section{Statistical analysis}

We plotted the prevalence (95\% confidence interval $[\mathrm{Cl}]$ ) of gestational diabetes mellitus per $1^{\circ} \mathrm{C}$ increase in the mean 30-day temperature before a woman's 27 th week of pregnancy.

We then used generalized estimating equations (PROC GENMOD, SAS/STAT software), using the logit link function, to examine the odds ratio (OR) for gestational diabetes mellitus per $10^{\circ} \mathrm{C}$ rise in mean temperature in the 30-day period before a woman's 27 th week of pregnancy. We adjusted this main model for maternal age, parity, world region of origin, neighbourhood income and fiscal year that the child was born. The generalized estimating equations model accounted for the potential clustering of more than 1 pregnancy from the same woman during the study period. We then reran the main model using the mean 30-day temperature exposure based on the actual date of the 50-g glucose challenge test, which was known for a subgroup of women screened at a nonhospital laboratory. 
In our next analysis, we used a generalized estimating equations model restricted to a subset of women with 2 or more consecutive pregnancies in the study period and, again, excluded those who developed diabetes between pregnancies. In this analysis, only the first 2 pregnancies were evaluated, enabling each woman to serve as her own control. We calculated an OR for developing gestational diabetes mellitus in relation to each $10^{\circ} \mathrm{C}$ rise in the temperature difference between pregnancies based on the 30-day period before screening: first, assuming screening occurred at the 27th week of gestation, and second using the known date of screening for gestational diabetes mellitus. Odds ratios were adjusted for maternal age and parity for each pregnancy. In these analyses, ORs were calculated irrespective of the order of each pregnancy or which had a warmer mean outdoor air temperature. Because pregnancy order was a statistically significant covariate in the latter, we then ran an unconditional logistic regression model and assessed the OR for developing gestational diabetes mellitus in the second pregnancy - in relation to the 30-day mean temperature before screening in the second pregnancy - adjusting for gestational diabetes mellitus in the first pregnancy, as well as both maternal age and parity in the second pregnancy.

We reran the main generalized estimating equations model for a subsample of women who underwent screening for gestational diabetes mellitus at Mount Sinai Hospital. However, in this analysis, diagnosis of gestational diabetes mellitus was based on results with highly abnormal serum glucose concentrations of $10.3 \mathrm{mmol} / \mathrm{L}$ or more on the 1 -hour 50 -g glucose challenge test the threshold at which women do not require further confirmatory testing with an oral glucose tolerance test. ${ }^{34}$

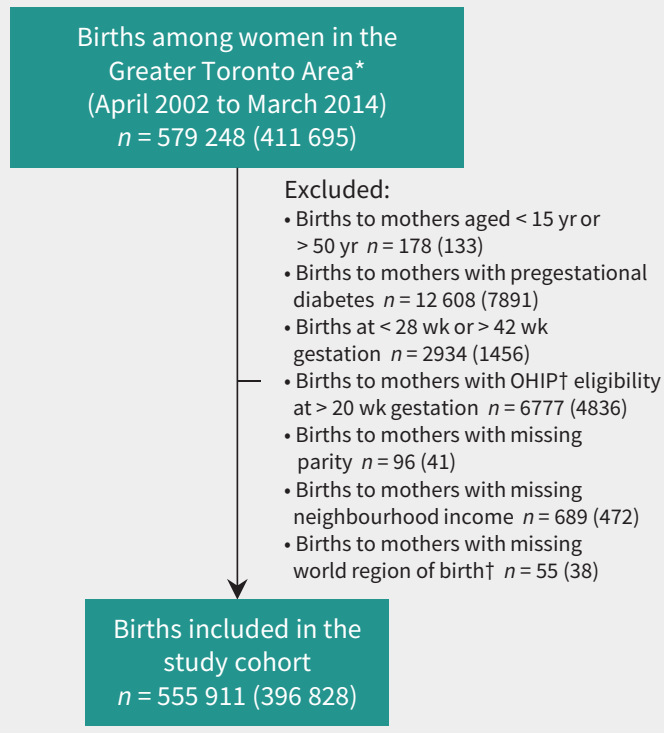

Figure 1: Creation of the study cohort. ${ }^{\star}$ Restricted to urban and suburban areas in Toronto and surrounding communities (Burlington, Oakville, Mississauga, Brampton, Richmond Hill, Vaughan, Markham, Pickering, Ajax, Whitby and Oshawa). †Among women who immigrated to Canada in 1985 or later. Values in brackets reflect the no. of women who gave birth. $\mathrm{OHIP}=$ Ontario Health Insurance Plan.

\section{Additional analyses}

We examined the prevalence $(95 \% \mathrm{Cl})$ of gestational diabetes mellitus per $1^{\circ} \mathrm{C}$ increment in mean outdoor air temperature stratified by whether the woman was born in a hotter-climate country or not (Appendix 1, available at www.cmaj.ca/lookup/ suppl/doi:10.1503/cmaj.160839/-/DC1). We also added prepreg-

Table 1: No. of births to women who underwent screening

for gestational diabetes in the Greater Toronto Area in Ontario (2002-2014), by maternal characteristic

\section{Maternal characteristic}

Age, mean $\pm S D$; yr

No. of previous births

0

1

$\geq 2$

World region of birth

Canada

Western Nations and Europe

Hispanic America

Caribbean

Sub-Saharan Africa

Middle East and North Africa

East Asia and Pacific

South Asia

Neighbourhood income

Q1 (lowest)

Q2

Q3

Q4

Q5 (highest)

Year child was born $\ddagger$

2002

2003

2004

2005

2006

2007

2008

2009

2010

2011

2012

2013
No. of births $(\%)^{*}$ $n=555911 \dagger$

$30.9 \pm 5.4$

259258 (46.6)

198578 (35.7)

98075 (17.6)

$307254(55.3)$

$32312(5.8)$

18350 (3.3)

$15872(2.9)$

17795 (3.2)

19737 (3.6)

62352 (11.2)

82239 (14.8)

150727 (27.1)

123193 (22.2)

102297 (18.4)

91686 (16.5)

88008 (15.8)

$33594(6.0)$

37844 (6.8)

49696 (8.9)

49599 (8.9)

49597 (8.9)

$50140(9.0)$

48416 (8.7)

47965 (8.6)

47103 (8.5)

$47466(8.5)$

47807 (8.6)

$46684(8.4)$

Note: $\mathrm{Q}=$ quintile, $\mathrm{SD}=$ standard deviation

*Unless specified otherwise.

†Total no. of births to 396828 women.

$\ddagger$ Fiscal year, from Apr. 1 of the indicated year to Mar. 31 of the subsequent year, as defined by Ontario's Ministry of Health and Long-Term Care. 
nancy BMI to our main generalized estimating equations model, by using a smaller subsample of 36935 pregnancies linked to the BORN data set at ICES.

\section{Ethics approval}

This study received ethical approval from ICES and the Research Ethics Board of Sunnybrook Health Sciences Centre, Toronto, Ont.

\section{Results}

The creation of the study cohort is outlined in Figure 1. Between Apr. 1, 2002, and Mar. 31, 2014, there were 555911 births among included women ( $n=396828$ ) living in the Greater Toronto Area. Among these, 133500 women had 2 or more births during the observation period. For 345853 births (62\%), screening for gestational diabetes mellitus was conducted at a nonhospital laboratory, and screening for 44110 births (8\%) was specifically undertaken at Mount Sinai Hospital, Toronto.

The mean age of participants at the time of child birth was 30.9 years in the overall sample, and nearly one-half of all births were to women born outside of Canada (Table 1). The characteristics of women with 2 or more births during the observation period ( $n=133500$ ) were similar to those of the entire cohort (Appendix 2, available at www.cmaj.ca/lookup/suppl/doi:10.1503/ cmaj.160839/-/DC1); however, women who underwent screening at Mount Sinai Hospital were somewhat older and more likely to be of higher socioeconomic status (Appendix 3, available at www. cmaj.ca/lookup/suppl/doi:10.1503/cmaj.160839/-/DC1).

Among all pregnancies ( $n=555911$ ), we determined (using hospital and laboratory claims data) that gestational diabetes mellitus occurred in 35879 (6.5\%). We observed a similar prevalence of gestational diabetes mellitus (6.3\%) among the cohort of women with 2 or more births during the observation period. Among pregnancies for which screening occurred at Mount Sinai Hospital ( $n=44110), 859$ (1.9\%) fulfilled the diagnostic criterion of a very high 1-hour glucose concentration of $10.3 \mathrm{mmol} / \mathrm{L}$ or more for the 50 -g glucose challenge test.

We found a direct relation between ambient temperature and prevalence of gestational diabetes mellitus (Figure 2). Prevalence of gestational diabetes mellitus among women exposed to a mean outdoor air temperature of $-10^{\circ} \mathrm{C}$ or lower in the preceding 30 days was $4.6 \%$ (95\% Cl 3.5\%-5.3\%), whereas prevalence of gestational diabetes mellitus among those exposed to a mean 30-day outdoor air temperature of $24^{\circ} \mathrm{C}$ or higher was $7.7 \%(95 \% \mathrm{Cl} 7.2 \%-8.2 \%)-$ an absolute difference of $3.1 \%$ (95\% Cl $2.2 \%-4.0 \%)$.

We found that each $10^{\circ} \mathrm{C}$ increase in mean 30-day outdoor air temperature was associated with a $1.06(95 \% \mathrm{Cl} 1.05-1.07)$ times higher adjusted odds of gestational diabetes mellitus when screening was assumed to have occurred at 27 weeks gestation (Table 2 and Figure 3, top). Results were remarkably similar using the mean 30-day outdoor air temperature before the known screening test date (Figure 3, second from top).

Among women with 2 consecutive pregnancies $(n=133500)$, we found a 1.06 times higher adjusted odds of having gestational diabetes mellitus per $10^{\circ} \mathrm{C}$ increase in the temperature difference between pregnancies (Figure 3, middle), irrespective of the order in which the pregnancy during warmer weather occurred (adjusted OR 1.06, 95\% Cl 1.05-1.08). Furthermore, the influence of temperature on the odds of gestational diabetes mellitus in the second pregnancy remained unaltered after adjusting for

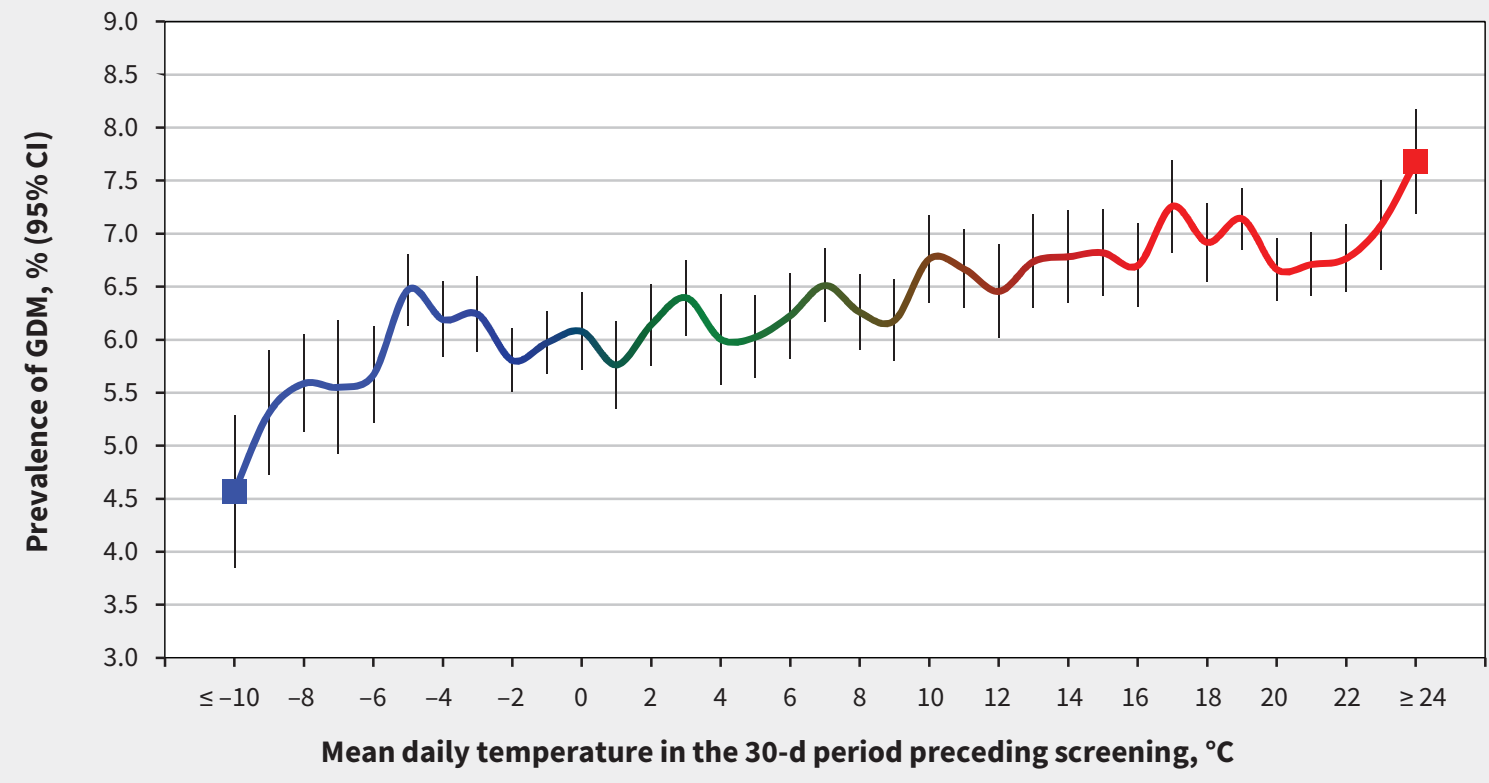

Figure 2: Mean daily outdoor air temperature over the 30-day period before screening for gestational diabetes mellitus (GDM) and corresponding crude prevalence (95\% confidence interval [vertical bars]) of GDM. Data are shown for pregnancies $(n=555911)$ that occurred in the Greater Toronto Area in Ontario, from 2002 to 2014. Crude and age-adjusted prevalences for GDM per $1^{\circ} \mathrm{C}$ rise in 30-day mean temperature were highly correlated $\left(R^{2}=0.997\right)$. Coldest (blue) to moderate (green) to hottest (red) temperatures are shown on the solid line. $\mathrm{Cl}=$ confidence interval. 
gestational diabetes mellitus in the first pregnancy (adjusted OR 1.06, 95\% Cl 1.03-1.09).

Among the subsample of women who underwent screening for gestational diabetes mellitus at Mount Sinai Hospital, we calculated an adjusted OR of 1.09 (95\% | 1.04-1.13) per $10^{\circ} \mathrm{C}$ temperature increment, when defining gestational diabetes mellitus based on glucose concentrations following a 50 -g glucose challenge test (Figure 3, bottom).

We found a positive relation between mean 30-day outdoor air temperature and prevalence of gestational diabetes mellitus among women born in hotter-climate or less hot countries, although rates of gestational diabetes mellitus were about $4 \%$ higher among the former (Appendix 4, available at www.cmaj. ca/lookup/suppl/doi:10.1503/cmaj.160839/-/DC1).

We restricted the main model to a small subsample of just 36935 pregnancies with known prepregnancy BMI and found an unadjusted $\mathrm{OR}$ per $10^{\circ} \mathrm{C}$ increase of 1.03 (95\% $\mathrm{Cl} 0.99-1.07$ ), which did not change upon adding BMI to the full model (adjusted OR 1.03, 95\% Cl 0.99-1.08).

\section{Interpretation}

We observed a direct relation between outdoor air temperature and the risk of gestational diabetes mellitus among nearly 400000 women residing in a single urban area in Canada. Within this confined geographical region, where there are wide fluctuations in temperature across seasons, the absolute difference in the rate of gestational diabetes mellitus was more than $3 \%$ between the hottest and coldest outdoor air temperatures. After adjusting for influential risk factors, each $10^{\circ} \mathrm{C}$ increase in mean 30-day outdoor air temperature was associated with a 6\%-9\% relative increase in the risk of gestational diabetes mellitus.

Our study design represents a natural experiment, in which observed variations in outdoor air temperature were linked to gestational diabetes mellitus. One strength of our study was our use of population-level data within a universal health care system, thereby minimizing selection bias. Furthermore, all included women were at a similar stage of pregnancy (i.e., at the transition from the second to third trimester, a period characterized by greater insulin resistance). Moreover, our findings were robust, whether we used validated administrative health records or actual serum glucose concentrations at the time of the standard 50-g glucose challenge test, and consistent among women born in hotter and colder climates. Although we studied a single geographical region, our findings are likely to be generalizable to other regions in North America and worldwide.

A growing body of research supports the biological plausibility of our findings. Studies using positron emission tomography and involving small numbers of participants have shown the presence of stores of functional brown adipose tissue in humans that can be stimulated by even brief exposure to cold temperatures, with an exposure to cold as short as 2 hours augmenting insulin sensitivity. ${ }^{6-15}$ In small trials involving humans, cold acclimatization over weeks or months was associated with an expansion of volume of brown adipose tissue and increases in both energy expenditure and insulin sensitivity. ${ }^{16-18}$ Furthermore,
Table 2: Odds ratios for gestational diabetes mellitus, by characteristics of the index pregnancy among included births to women who underwent screening in the Greater Toronto Area in Ontario (2002-2014)*

Characteristic
Mean outdoor air temperature
over the 30-day period before
27 th wk of pregnancy per $10^{\circ} \mathrm{C}$
increment

Age per 1-yr increment

Parity

0

1

$\geq 2$

Unadjusted OR $(95 \% \mathrm{Cl})$

$1.07(1.06-1.08)$ $(95 \% \mathrm{Cl}) \dagger$

Neighbourhood income

Q1 (lowest)

Q2

Q3

Q4

Q5 (highest)

World region of birth

Canada

Western Nations and Europe

Hispanic America

Caribbean

Sub-Saharan Africa

Middle East and North Africa

East Asia and Pacific

South Asia

Year child was born $\ddagger$

2002

2003

2004

2005

2006

2007

2008

2009

2010

2011

2012

2013
$1.08(1.07-1.08)$

$1.09(1.09-1.10)$

$\begin{array}{cc}1.00 \text { (ref) } & 1.00 \text { (ref) } \\ 1.12(1.09-1.14) & 0.87(0.85-0.89) \\ 1.45(1.41-1.49) & 0.92(0.89-0.94)\end{array}$

$\begin{array}{cc}1.00 \text { (ref) } & 1.00 \text { (ref) } \\ 0.90(0.87-0.92) & 0.93(0.90-0.96) \\ 0.79(0.77-0.82) & 0.85(0.82-0.88) \\ 0.66(0.64-0.69) & 0.73(0.71-0.76) \\ 0.51(0.49-0.53) & 0.55(0.53-0.58)\end{array}$

1.00 (ref)

1.00 (ref)

$0.94(0.88-1.00)$

$0.89(0.85-0.95)$

1.55 (1.46-1.65)

$1.49(1.40-1.60)$

$1.42(1.32-1.52)$

$1.42(1.32-1.53)$

$1.50(1.40-1.60)$

1.27 (1.19-1.36)

$1.47(1.38-1.56)$

$1.38(1.30-1.47)$

$2.04(1.97-2.12)$

$1.70(1.64-1.76)$

$2.80(2.72-2.89)$

$2.95(2.85-3.04)$

$$
1.00 \text { (ref) }
$$

1.00 (ref)

$1.05(0.98-1.13)$

1.02 (0.95-1.09)

$1.33(1.25-1.41)$

$1.21(1.14-1.29)$

$1.40(1.32-1.49)$

$1.26(1.18-1.33)$

1.51 (1.42-1.60)

1.33 1.25-1.41)

1.47 (1.39-1.56)

1.27 (1.19-1.35)

1.78 (1.68-1.89)

1.53 (1.44-1.62)

1.84 (1.74-1.95)

$1.56(1.46-1.65)$

1.76 (1.66-1.87)

$1.46(1.37-1.56)$

1.79 (1.68-1.90)

$1.48(1.39-1.57)$

$1.86(1.75-1.97)$

$1.53(1.44-1.62)$

1.62 (1.52-1.72)

$1.33(1.25-1.41)$
Note: $\mathrm{Cl}=$ confidence interval, $\mathrm{OR}=$ odds ratios, $\mathrm{Q}=$ quintile, ref $=$ referent

*No. of included births, $n=555911$; no. of included women, $n=396828$.

tOdds ratios are adjusted for all variables listed in the table.

IFiscal year, from Apr. 1 of the indicated year to Mar. 31 of the subsequent year, as

defined by Ontario's Ministry of Health and Long-Term Care. 
there appears to be an inverse relation between activity of brown adipose tissue and both BMI and visceral adiposity. ${ }^{10-14}$ Seasonal fluctuations in dysglycemia were observed among a sample of pregnant women $(n=997)$ living in in a small region of Australia. ${ }^{35}$

\section{Limitations}

Although our study focused on outdoor rather than indoor air temperatures, the latter are about $5^{\circ} \mathrm{C}$ higher at hotter times of the year. ${ }^{36}$ In a study carried out in Greater Boston, Massachusetts - a region with a similar climate to the Greater Toronto Area - there was a strong correlation between average indoor and outdoor air temperature when outdoor temperatures rose above $13^{\circ} \mathrm{C} .{ }^{37} \mathrm{As}$ outdoor temperature fell below $13^{\circ} \mathrm{C}$, the average indoor temperature remained steady at $18^{\circ} \mathrm{C}$. Therefore, our use of outdoor warm temperature as a reflection of personal temperature exposure was likely valid; however, on cooler days, we may not have optimally captured personal temperature exposure, an effect that would have biased our findings toward the null. 30-day period

Before 27 wk gestation, comparing all women

Before GDM screening date, comparing all women

Before 27 weeks gestation, comparing temperature difference between 2 consecutive pregnancies for the same woman

Before GDM screening date, comparing temperature difference between 2

consecutive pregnancies for the same woman

Before GDM screening date, comparing all women with a recorded glucose challenge test result $\geq 10.3 \mathrm{mmol} / \mathrm{L}$
No. with GDM/no. at risk (\% with GDM)

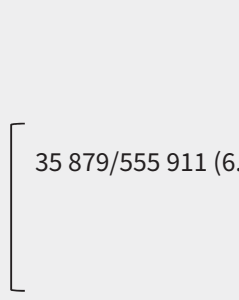

[

24 128/345 $853(7.0)$

$8442 / 133500(6.3)$

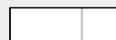

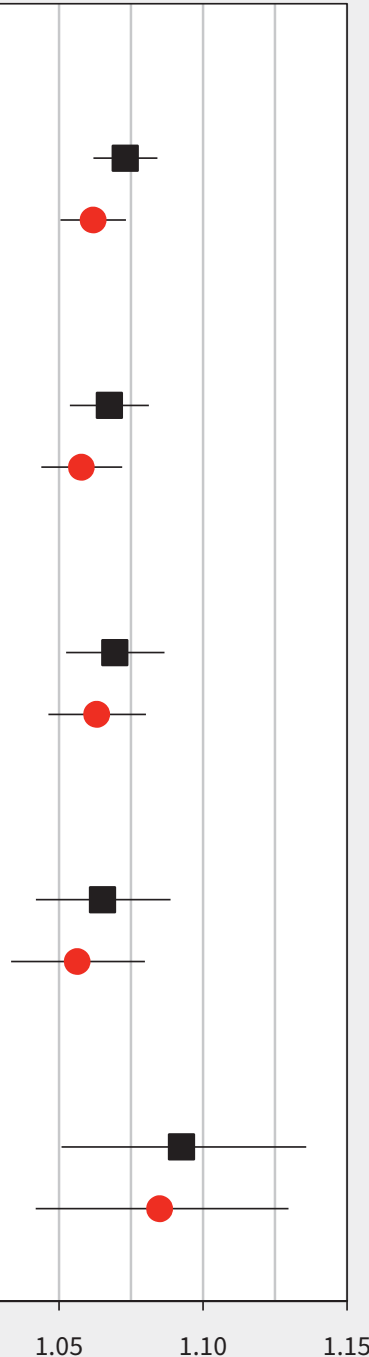

OR $(95 \% \mathrm{Cl})$

per $10^{\circ} \mathrm{C}$ increase in temperature*

Figure 3: Relative odds of gestational diabetes mellitus (GDM; unadjusted [black squares] and adjusted [red circles] odds ratios [95\% $\mathrm{CI}$ ) per $10^{\circ} \mathrm{C}$ increase in mean daily outdoor air temperature over a 30-day period before screening for GDM. The top 2 models (green text) include all pregnancies, by the 30-day period before 27 weeks gestation and the 30-day period before the actual date of screening, adjusted for maternal age, parity, income quintile, world region and year. The middle 2 models (blue text) include only women with 2 consecutive pregnancies, adjusted for maternal age and parity for each pregnancy. The bottom model (orange text) includes only the subgroup of women with serum glucose results for the 50-g glucose challenge test, adjusted for maternal age, parity, income quintile, world region and year. $\mathrm{Cl}=$ confidence interval, $\mathrm{OR}=$ odds ratio. 
There are several other limitations to our study that merit discussion. We had information on prepregnancy BMI for only $6.6 \%$ of births, and no information on weight gain during pregnancy, activity level or diet. ${ }^{38,39}$ In Canada, levels of physical activity are generally lower in colder winter months, with less daylight than in the summer; ${ }^{40,41}$ yet, we found that the rate of gestational diabetes mellitus was lowest with cold outdoor air temperatures. It is possible that some women with pregestational diabetes may have been misclassified as having gestational diabetes mellitus owing to incomplete capture of such cases by the Ontario Diabetes Database. However, such misclassification would have minimally affected our findings, given the low prevalence of diabetes in women of reproductive age and no indication for screening for gestational diabetes mellitus in women with pregestational diabetes. ${ }^{22}$

Although cold exposure has been shown to have direct effects on brown adipose tissue and insulin sensitivity, ${ }^{7-12,15-18}$ neither could be measured in our population. The relation between temperature and gestational diabetes mellitus persisted when comparing 2 consecutive pregnancies within the same woman, which suggests a lack of influence of unmeasured confounding. Although our findings are not easily explained by competing hypotheses, the biological mechanism for the association we observed requires further investigation.

\section{Conclusion}

Our findings have implications for the prevention and management of gestational diabetes mellitus. If the association between air temperature and risk of gestational diabetes mellitus is real, then modifying the thermal environment (e.g., lowering the setting on a home thermostat or spending more time outdoors in cooler weather) may reduce risk of gestational diabetes mellitus. Moreover, it raises some broader questions. Climate change models forecast that the earth's surface temperature will rise by $1-2^{\circ} \mathrm{C}$ by the year 2050, with the greatest increase in colder climate regions. ${ }^{1,2}$ If these assumptions are correct, and our current findings are valid, then we would expect an increase in the number of cases of gestational diabetes mellitus worldwide. Although changes in temperature of this size may lead to a small relative increase in the risk of gestational diabetes mellitus, the absolute number of women affected in Canada and elsewhere may be substantial.

\section{References}

1. Zwiers FW. Climate change: the 20-year forecast. Nature 2002;416:690-1.

2. Allen MR, Stott PA, Mitchell JF, et al. Quantifying the uncertainty in forecasts of anthropogenic climate change. Nature 2000;407:617-20.

3. Haines A, Patz JA. Health effects of climate change. JAMA 2004;291:99-103.

4. Betz MJ, Enerbäck S. Human brown adipose tissue: what we have learned so far. Diabetes 2015;64:2352-60.

5. Kajimura S, Spiegelman BM, Seale P. Brown and beige fat: physiological roles beyond heat generation. Cell Metab 2015;22:546-59.

6. Virtanen KA, Lidell ME, Orava J, et al. Functional brown adipose tissue in healthy adults. N Engl J Med 2009;360:1518-25.

7. Celi FS, Brychta RJ, Linderman JD, et al. Minimal changes in environmental temperature result in a significant increase in energy expenditure and changes in the hormonal homeostasis in healthy adults. Eur J Endocrinol 2010;163:863-72.
8. Ouellet V, Labbé SM, Blondin DP, et al. Brown adipose tissue oxidative metabolism contributes to energy expenditure during acute cold exposure in humans. J Clin Invest 2012;122:545-52.

9. Chen KY, Brychta RJ, Linderman JD, et al. Brown fat activation mediates coldinduced thermogenesis in adult humans in response to a mild decrease in ambient temperature. J Clin Endocrinol Metab 2013;98:E1218-23.

10. Matsushita M, Yoneshiro $\mathrm{T}$, Alta $\mathrm{S}$, et al. Impact of brown adipose tissue on body fatness and glucose metabolism in healthy humans. Int $\mathrm{J}$ Obes (Lond) 2014;38:812-7.

11. van Marken Lichtenbelt WD, Vanhommerig JW, Smulders NM, et al. Cold-activated brown adipose tissue in healthy men. NEngl J Med 2009;360:1500-8.

12. Saito M, Okamatsu-Ogura $Y$, Matsushita M, et al. High incidence of metabolically active brown adipose tissue in healthy adult humans: effects of cold exposure and adiposity. Diabetes 2009;58:1526-31.

13. Cypess AM, Lehman S, Williams G, et al. Identification and importance of brown adipose tissue in adult humans. N Engl J Med 2009;360:1509-17.

14. Ouellet V, Routhier-Labadie A, Bellemere W, et al. Outdoor temperature, age, sex, body mass index, and diabetic status determine the prevalence, mass, and glucose-uptake activity of 18F-FDG-detected BAT in humans. J Clin Endocrinol Metab 2011;96:192-9.

15. Chondronikola M, Volpi E, Børsheim E, et al. Brown adipose tissue improves whole-body glucose homeostasis and insulin sensitivity in humans. Diabetes 2014;63:4089-99.

16. Lee $\mathrm{P}, \mathrm{Smith} \mathrm{S}$, Linderman J, et al. Temperature-acclimated brown adipose tissue modulates insulin sensitivity in humans. Diabetes 2014;63:3686-98.

17. Hanssen MJ, Hoeks J, Brans B, et al. Short-term cold acclimation improves insulin sensitivity in patients with type 2 diabetes mellitus. Nat Med 2015;21:863-5.

18. van der Lans AA, Hoeks J, Brans B, et al. Cold acclimation recruits human brown fat and increases nonshivering thermogenesis. J Clin Invest 2013;123:3395-403.

19. Barbour LA, McCurdy CE, Hernandez TL, et al. Cellular mechanisms for insulin resistance in normal pregnancy and gestational diabetes. Diabetes Care 2007;30(Suppl 2):S112-9.

20. IDF diabetes atlas. 7th ed. Brussels (Belgium): International Diabetes Federation; 2015. Available: www.diabetesatlas.org (accessed 2016 May 13).

21. Catalano PM, McIntyre DH, Cruickshank KJ, et al.; HAPO Study Cooperative Research Group. The hyperglycemia and adverse pregnancy outcome study: associations of GDM and obesity with pregnancy outcomes. Diabetes Care 2012;35:780-6

22. Feig DS, Hwee J, Shah BR, et al. Trends in incidence of diabetes in pregnancy and serious perinatal outcomes: a large, population-based study in Ontario, Canada, 1996-2010. Diabetes Care 2014;37:1590-6.

23. Feig DS, Shah BR, Lipscombe LL, et al. Preeclampsia as a risk factor for diabetes: a population-based cohort study. PLoS Med 2013;10:e1001425.

24. Greater Toronto Area. Wikipedia [updated December 2015]. Available: https:// en.wikipedia.org/wiki/Greater_Toronto_Area (accessed 2016 Feb. 25).

25. CIHI data quality study of the 2006-2007 Discharge Abstract Database. Ottawa: Canadian Institute for Health Information; 2009. Available: https://secure.cihi. ca/free_products/DAD_2006-07_Main_Report\%20_en_web.pdf (accessed 2016 Dec. 6).

26. CIHI data quality study of the 2005-2006 Discharge Abstract Database. Ottawa: Canadian Institute for Health Information; 2009. Available: https://secure.cihi. ca/free_products/DAD_DQ_study_2005_2006_August_2009_e.pdf (accessed 2016 Dec. 6).

27. Vigod SN, Gomes T, Wilton AS, et al. Antipsychotic drug use in pregnancy: high dimensional, propensity matched, population based cohort study. BMJ 2015;350:h2298

28. Hux JE, Ivis F, Flintoft V, et al. Diabetes in Ontario: determination of prevalence and incidence using a validated administrative data algorithm. Diabetes Care 2002;25:512-6. 
29. Canadian Diabetes Association Clinical Practice Guidelines Expert Committee. Canadian Diabetes Association 2003 clinical practice guidelines for the prevention and management of diabetes in Canada. Can J Diabetes 2003;27(Suppl 2): S168-80.

30. Canadian Diabetes Association Clinical Practice Guidelines Expert Committee. Canadian Diabetes Association 2008 clinical practice guidelines for the prevention and management of diabetes in Canada. Can J Diabetes 2008;32(Suppl 1): S94-8.

31. Bowker SL, Savu A, Lam NK, et al. Validation of administrative data case definitions for gestational diabetes mellitus. Diabet Med 2017;34:51-5.

32. Urquia $\mathrm{M}$, Glazier $\mathrm{RH}$, Berger $\mathrm{H}$, et al. Gestational diabetes among immigrant women. Epidemiology 2011;22:879-80.

33. Kliewer EV, Kazanjian A. The health status and medical services utilization of recent immigrants to Manitoba and British Columbia: a pilot study. BC Office of Health Technology Assessment, Centre for Health Services and Policy Research, University of British Columbia; 2000

34. Meltzer SJ, Snyder J, Penrod JR, et al. Gestational diabetes mellitus screening and diagnosis: a prospective randomised controlled trial comparing costs of one-step and two-step methods. BJOG 2010;117:407-15.
35. Moses RG, Wong VC, Lambert K, et al. Seasonal changes in the prevalence of gestational diabetes mellitus. Diabetes Care 2016;39:1218-21.

36. Wallace LA, Emmerich SJ, Howard-Reed C. Continuous measurements of air change rates in an occupied house for 1 year: the effect of temperature, wind, fans, and windows. J Expo Anal Environ Epidemiol 2002;12:296-306.

37. Nguyen JL, Schwartz J, Dockery DW. The relationship between indoor and outdoor temperature, apparent temperature, relative humidity, and absolute humidity. Indoor Air 2014;24:103-12.

38. De Souza LR, Berger H, Retnakaran R, et al. First-trimester maternal abdominal adiposity predicts dysglycemia and gestational diabetes mellitus in midpregnancy. Diabetes Care 2016;39:61-4.

39. Kim SY, Sharma AJ, Sappenfield W, et al. Association of maternal body mass index, excessive weight gain, and gestational diabetes mellitus with large-forgestational-age births. Obstet Gynecol 2014;123:737-44.

40. Merrill RM, Shields EC, White GL Jr, et al. Climate conditions and physical activity in the United States. Am J Health Behav 2005;29:371-81.

41. Eisinga R, Franses PH, Vergeer M. Weather conditions and daily television use in the Netherlads, 1996-2005. Int J Biometeorol 2011;55:555-64.

\section{Competing interests: None declared.}

This article has been peer reviewed.

Accepted: Dec. 28, 2016

Affiliations: Departments of Medicine (Booth, Ray) and Obstetrics and Gynecology (Ray), St. Michael's Hospital; Institute for Clinical Evaluative Sciences (Booth, Luo, Park, Feig, Moineddin, Ray); Department of Medicine (Feig), Mount Sinai Hospital; Department of Family and Community Medicine (Moineddin), and Department of Medicine (Booth, Feig, Ray), University of Toronto, Toronto, Ont.

Contributors: Gillian Booth and Joel Ray were responsible for the conception and design of the study and drafted the article. Jin Luo, Alison Park and Rahim Moineddin performed the statistical analyses. All of the authors contributed to the interpretation of data, critically revised the article for important intellectual content, gave final approval of the version to be published and agreed to be accountable for all aspects of the work.

Funding: This study was funded by the St. Michael's Hospital Foundation and the Canadian Institutes of Health Research (CIHR). Gillian Booth is supported by a Mid-Career Investigator Award from the Heart and Stroke Foundation of Ontario. Joel Ray is supported by a CIHR Reproductive and Child Health Services and Policy Research Chair. Further support was provided by the Institute for Clinical Evaluative Sciences, which receives funding through an annual grant from the Ontario Ministry of Health and LongTerm Care.

Disclaimer: This study was supported by the Institute for Clinical Evaluative Sciences (ICES), which is funded by an annual grant from the Ontario Ministry of Health and Long-Term Care (MOHLTC). The opinions, results and conclusions reported in this paper are those of the authors and are independent from the funding sources. No endorsement by ICES or the Ontario MOHLTC is intended or should be inferred.

Parts of this material are based on data and information compiled and provided by the Canadian Institute for Health Information (CIHI). However, the analyses, conclusions, opinions and statements expressed herein are those of the authors, and not necessarily those of $\mathrm{ClHI}$.

Correspondence to: Gillian Booth, boothg@ smh.ca 